\title{
Analisis Followers to Likes Ratio Tiktok Pada 10 Influencer Tiktok Terbaik Indonesia
}

\author{
I Dewa Gede Gilang Arwika
}

Email: dewagilang130901@gmail.com

\begin{abstract}
The development of information technology brings a change in society. The birth of social media makes people's behavior patterns experience a shift in culture, ethics and existing norms. Indonesia with a large population with various ethnic, racial and religious cultures has a lot of potential for social change. In this era of globalization, technology is increasingly advanced, it is undeniable that the presence of the internet is increasingly needed among people in daily life, be it socialization activities, education, business, and so on. For the community, especially teenagers, social media has become an addiction that makes users no day without opening social media. Whereas in its development period, in school, teenagers try to find their identity by hanging out with their peers. In this study, the researcher intends to explore the facts, symptoms and events of the influence of social media on adolescent behavior in the field as it is in the context of space and time as well as the natural environment of adolescents.
\end{abstract}

Keywords: Change; Social Media; Needs

\begin{abstract}
ABSTRAK
Perkembangan teknologi informasi membawa sebuah perubahan dalam masyarakat. Lahirnya media sosial menjadikan pola perilaku masyarakat mengalami pergeseran baik budaya, etikan dan norma yang ada. Indonesia dengan jumlah penduduk yang besar dengan berbagai kultur suku, ras dan agama yang beraneka ragam memiliki banyak sekali potensi perubahan sosial. Era globalisasi ini teknologi semakin maju, tidak dapat dipungkiri hadirnya internet semakin dibutuhkan di kalangan masyarakat dalam kehidupan sehari-hari, baik itu kegiatan sosialisasi, pendidikan, bisnis, dan sebagainya. Bagi masyarakat khususnya kalangan remaja, media sosial sudah menjadi candu yang membuat penggunanya tiada hari tanpa membuka media sosial. Padahal dalam masa perkembangannya, di sekolah remaja berusaha mencari identitasnya dengan bergaul bersama teman sebayanya. Dalam penelitian ini, peneliti bermaksud ingin mendalami suatu fakta, gejala dan peristiwa pengaruh media sosial terhadap perilaku remaja di lapangan sebagaimana adanya dalam konteks ruang dan waktu serta situasi lingkungan remaja secara alami.
\end{abstract}

Kata Kunci : Perubahan; Media Sosial; Kebutuhan

\section{PENDAHULUAN}

Media Sosial memiliki berbagai manfaat untuk manusia di era modern seperti saat ini, media sosial meghapus batasan - batasan manusia untuk bersosialisasi, batasan ruang maupun waktu, dengan media sosial manusia dimungkinkan untuk berkomunikasi satu sama lain dimanapun mereka bereda dan kapanpun, tidak peduli seberapa jauh jarak mereka dan mereka memiliki perasaan yang nyaman menggunakan media sosial yang dapat kita bilang media baru ini. (Structures, n.d.) 
Media sosial memiliki berbagai maanfaat yaitu ; sekedar untuk berkomunikasi dengan orang lain, untuk mencari tahu perkembangan sesuatu, untuk berbagi informasi maupun untuk mengikuti salah satu yang menjadi trend saat ini yaitu menggunakan media sosial sebagai bentuk eksistensi diri. Orang-orang yang hanya ingin menggunakan media sosial sebagai sarana menjaga silaturahmi biasanya akan memilih media sosial yang bersifat private saja seperti Line, Whatsapp, Path, Telegram, Blackberry Messenger atau yang lainnya. Meskipun masuk ke media yang terbuka seperti Facebook dan Twitter maka mereka hanya akan menjadi penonton dan pembaca yang baik dan melihat perkembangan terbaru yang ada di media sosial. Sedangkan bagi orang-orang yang ingin diakui eksistensinya oleh masyarakat luas melalui media sosial biasanya akan menggunakan media sosial yang bersifat terbuka seperti Instagram, Facebook, Line, atau Twitter. Karena disinilah tempat kita bisa secara bebas dan terbuka dalam berinteraksi. Sehingga banyaknya update status serta posting-an yang kita miliki adalah salah satu bentuk jika kita ingin dikenal secara luas. Kita dikenal sebagai apa dan siapa itu kita yang memutuskan, karena apa yang kita posting melalui media sosial akan menjadi gambaran diri kita bagaimana kita memposisikan diri dimata masyarakat luas. (Wylęgała, 2010)

Perkembangan teknologi informasi dan komunikasi telah mengubah cara interaksi individu dengan individu yang lain. Jika dilihat pada zaman dulu manusia atau seseorang yang ingin menceritakan perasaannya membutuhkan orang lain untuk mendengarkan ceritanya tersebut, keadaan tersebut bergeser dengan hadirnya buku tempat menuliskan curahan hati atau perasaan yang dikenal sebagai buku diary. Sekarang masyarakat berada pada arus perubahan yang sangat cepat akibat media sosial. (Moos, 1984)

\section{TINJAUAN PUSTAKA}

TikTok adalah sebuah jaringan sosial dan platform video musik Tiongkok yang dluncurkan pada September 2016 oleh Zhang Yiming, pendiri Toutiao. Aplikasi tersebut membolehkan para pemakai untuk membuat video musik pendek mereka sendiri. Melalui Tiktok pengguna dapat mengunggah foto dan video pendek kemudian membagikannya kepada pengguna lain. Pada gambar yang diunggah, pengguna dapat menambahkan tag kepada orang tertentu dan penentuan lokasi. Pengguna juga dapat mengatur akun mereka sebagai "pribadi", sehingga mengharuskan mereka menyetujui setiap permintaan pengikut baru. Pengguna dapat menghubungkan akun Tiktok mereka ke situs jejaring sosial lain, memungkinkan mereka untuk berbagi video yang diunggah ke situs-situs tersebut.(Ii, 2018)

Definisi media sosial yaitu suatu komunitas online untuk membagi informasi, ide, pendapat, pesan, dan video antar sesama penggunanya. Pengertian lain media sosial yaitu aplikasi atau website yang dapat digunakan penggunanya untuk menciptakan dan menyebarkan konten kepada jejaring sosial (misalnya teman, pengikut, dan sebagainya) yang dibangun untuk dirinya sendiri. Bentuk media sosial sangatlah bermacam-macam. Jejaring sosial adalah bentuk prototipe dari media sosial. Bentuk media sosial tidak hanya mencakup 
jejaring sosial, melainkan juga mencakup kategori media sharing, social news, dan kolaborasi konten lainnya.

Penggunaan istilah media sosial sering bertumpang tindih dengan jejaring sosial atau cakupan media sosial yang lain. Hal ini dikarenakan situs-situs media sosial tidak hanya terdiri dari satu jenis kategori seperti jejaring sosial saja, namun juga mencantumkan kategori lainnya. Contohnya yaitu situs seperti youtube, flickr, ataupun instagram, tiktok, selain menjadi media sharing untuk video atau gambar, juga menjadi jejaring sosial dikarenakan memiliki fitur seperti profil, komentar, dan feedback.(Fallis, 2013)

\section{METODOLOGI PENELITIAN}

Dalam kasus penelitian ini, peneliti menggunakan metode eksploratif kuantitatif untuk mengetahui kredibilitas dari akun Tiktok Pada 10 Influencer Terbaik di Indonesia.

Dari penelitian ini bertujuan untuk mengetahui nilai kredibilitas dari performa akun Tiktok Pada 10 Influencer Terbaik di Indonesia. Dalam perhitungan ini, terdapat beberapa langkah yang harus dilakukan dalam penelitian ini, sehingga mampu menemukan peringkat pertama akun Tiktok Pada 10 Influencer Terbaik di Indonesia yang memiliki performa terbaik. Langkah langkah yang dilakukan pada penelitian ini, yaitu:

\section{Melakukan Eksplorasi Pada Website Untuk Menentukan Objek Yang Akan Dianalisa.}

Eksplorasi ini dilakukan pada beberapa halaman website yang menyediakan informasi mengenai objek yang akan di teliti. Setelah eksplorasi tersebut selesai dilakukan, akan ditemukan nama nama Tiktok Pada 10 Influencer Terbaik di Indonesia yang akan dijadikan objek analisa. Langkah selanjutnya adalah mencari nama akun Tiktok dari masing-masing Influencer Indonesia dan pastikan semua Influencer mempunyai akun pada aplikasi sosial media Tiktok.

\section{Menghitung Nilai Rata-Rata Variable Dari 5 Youtuber Indonesia dengan Subscribe Terbanyak.}

Dalam langkah ini, peneliti melalukan perhitungan nilai variable followers to likes. Variable merupakan segala sesuatu yang akan menjadi objek dalam sebuah penelitian (Astriani, 2014). Untuk menghitung nilai rata rata dari variable followers to likes yaitu dengan cara mengambil data di Tiktok di hitung sehingga menemukan nilai rata-rata dari masing masing variable.

\section{Menghitung Nilai Kredibilitas Rasio.}

Dalam menghitung nilai kredibilitas dari video comments to image comments ratio, peneliti menggunakan cara membagi nilai variable pertama dengan variable kedua. Jika Followers mempunyai nilai 400.000 dan Likes memiliki nilai 800.000, maka cara menghitungnya yaitu $400.000: 800.000=0,5$. Dengan demikian dapat diperoleh hasil nilai dari followers to likes ratio adalah 0,5 .

\section{Menentukan Peringkat Pada Akun Tiktok.}


Langkah yang terakhir dalam penelitian ini yaitu menentukan peringkat dari masing masing rasio yang ada. Saat menentukan peringkat perlu melihat karakteristik dari rasio yang di teliti. Jika karakteristik rasio bernilai tinggi, maka objek yang akan memiliki nilai tinggi akan mendapat angka 10 dan objek yang memperoleh nilai tinggi akan mendapatkan angka 1. Setelah mendapatkan hasil kredibilitas ratio maka dapat disimpulkan objek yang mana yang memperoleh peringkat 1 sampai dengan peringkat 10.

\section{HASIL DAN PEMBAHASAN}

Akun Tiktok dari 10 Influencer Terbaik di Indonesia, diantaranya :

1. Sandy.ss

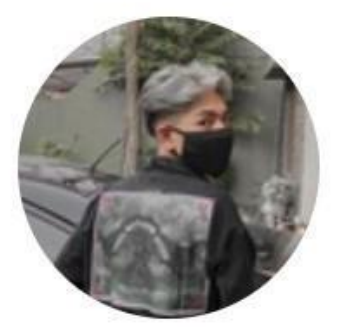

\section{sandys.ss}

SS

\section{Ikuti}

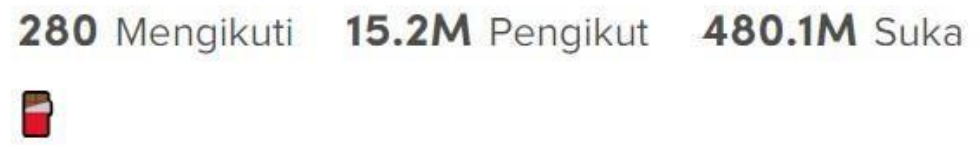

Gambar 1. Akun Tiktok Sandy.ss

Sumber : https://vt.tiktok.com/ZSeCpDLG9/ (akses pada 15-01-2022)

2. Cahyanirynn

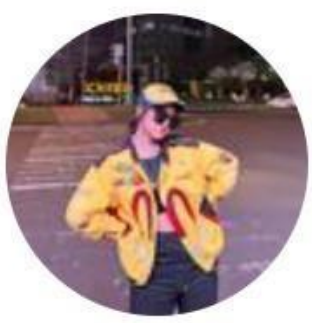

\section{cahyanirynn}

\section{Cahyaniryn}

\section{Ikuti}

\section{Mengikuti 17M Pengikut 948.1M Suka}

Brand Ambassador @teamrrq

follow igku:cahyanirynt

Gambar 2. Akun Tiktok Cahyanirynn

Sumber: https://vt.tiktok.com/ ZSeCpBTCr/ (akses pada 15-01-2022) 
3. Riaricis

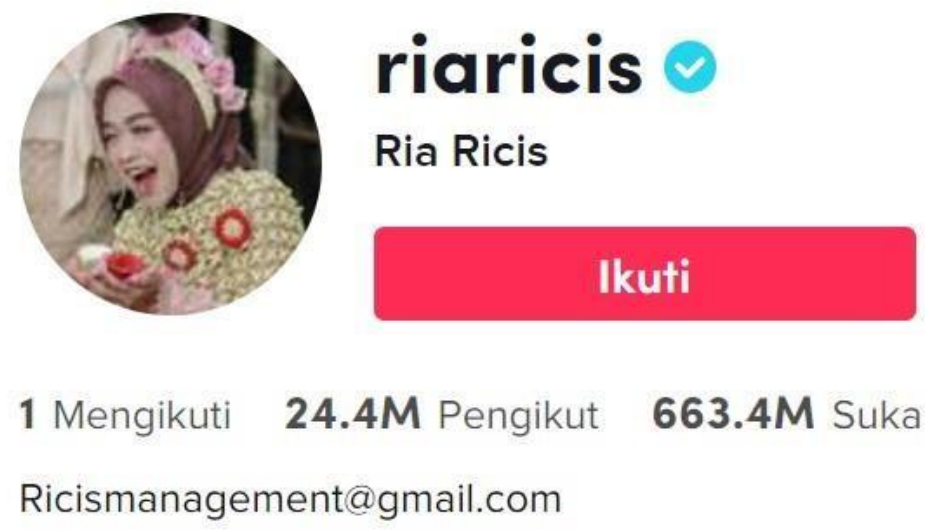

Gambar 3. Akun Tiktok Riaricis

Sumber https://vt.tiktok.com/ZSeCpxaqY/ (akses pada 15-01-2022)

4. Jharnabhagwani

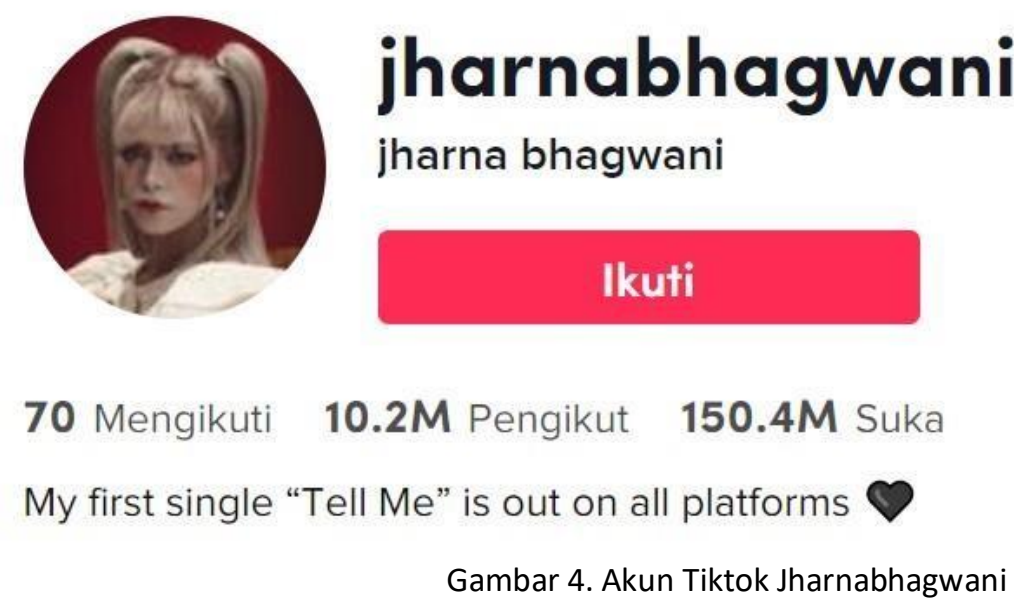

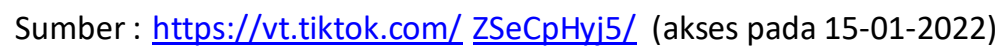

5. Aaalhaerid 


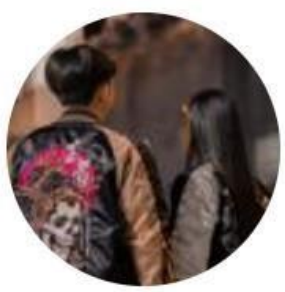

saalhaerid

AboveツSaid ID

\section{Ikuti}

47 Mengikuti 12.4M Pengikut 255.1M Suka

Jangan lupa follow instagram saya $\mathbb{P}$

Subscribe youtube aku yaa $\downarrow$

18 yo

Gambar 5. Akun Tiktok saalhaerid

Sumber: https://vt.tiktok.com/ZSeCpyu6Y/ (akses pada 15-01-2022)

6. Notnot8

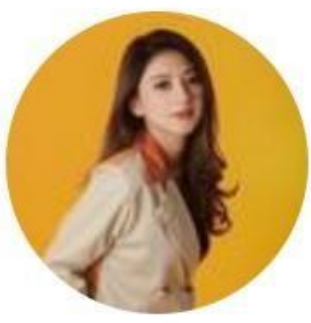

\section{notnot8}

NOTNOT

\section{Ikuti}

\section{Mengikuti 15.8M Pengikut 177.2M Suka \\ M}

Gambar 6. Akun Tiktok Notnot8

Sumber : https://vt.tiktok.com/ZSeCpfRGQ/ (akses pada 15-01-2022)

7. Dinda_ans

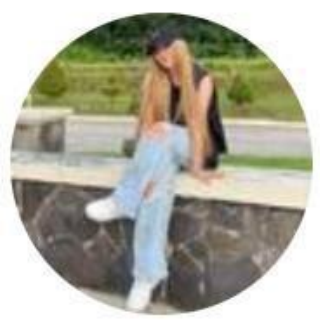

\section{dinda_ans}

\section{AboveツDinda ID}

\section{Ikuti}

50 Mengikuti 11.8M Pengikut 226.9M Suka

Akun Real Success Slim cuman disini $\left[\begin{array}{c}\text { s } \\ \text { A }\end{array}\right.$

Gambar 7. Akun Tiktok Dinda_ans

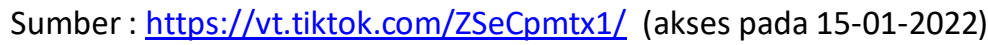

8. Dafaatmaja 


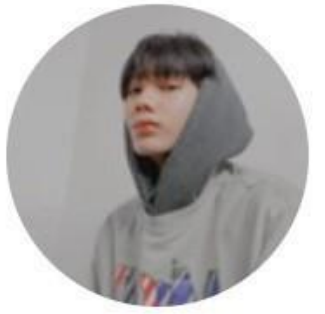

dafaatmja

Dafaatmja

\section{Ikuti}

54 Mengikuti 10M Pengikut 141.8M Suka

insta :@dafaatmja

等它

Gambar 8. Akun Tiktok Dafaatmaja

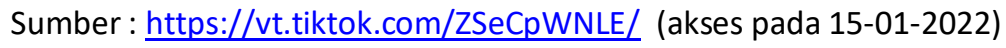

9. Juyyputrii21

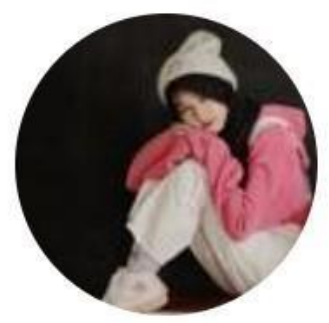

\section{juyyputrii21}

Juyycomell $\mathbb{H}^{3}$

\section{Ikuti}

1 Mengikuti 17M Pengikut 425.6M Suka

KEEPSUPORT

Folls instagrm ku@juyyputrii bntu 5jt folls $\bigcirc \in$

Gambar 9. Akun Tiktok Juyyputrii21

Sumber : https://vt.tiktok.com/ZSeCpn79U/ (akses pada 15-01-2022)

10. Realsesesvana

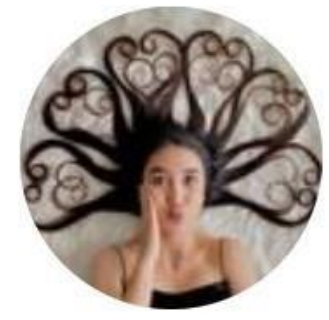

\section{realsesesvana} seses rapunzel 解

\section{Ikuti}

412 Mengikuti 9.3M Pengikut 150.2M Suka

22 yo

S youtu.be/gB21H4am2EY

Gambar 10. Akun Tiktok Realsesesvana

Sumber: https://vt.tiktok.com/ZSeCpCwpA/ (akses pada 15-01-2022) 
Dari kesepuluh akun Tiktok 10 Influencer Terbaik di Indonesia, peneliti menemukan nilai dari masing - masing variabel yang ada untuk menghitung rasio Followers to Likes dari setiap akun. Pada akun Tiktok terdapat 8 variabel, diantaranya yaitu :

1. Likes

2. Followers

3. Following

4. Video Likes

5. Video Comments

6. Video Share

7. Video Views

8. Post

Dari kedelapan variabel tersebut peneliti hanya fokus untuk menemukan hasil dari 2 variabel, yaitu :

1. Followers

2. Likes

Dari kedua variabel tersebut kemudian dianalisa sehingga menemukan nilai rata-rata dari variabel Followers to Likes. Untuk menghitung nilai rata-rata dari variabel followers to likes yaitu dengan cara mengambil data pada 10 akun Tiktok kemudian di hitung sehingga menemukan nilai ratarata dari masing-masing variabel. Berikut merupakan tabel nilai rata-rata dari masing-masing Influencer Terbaik di Indonesia, yaitu :

Tabel 1. Analisa Followers to Likes Ratio Tiktok pada 10 Influencer Terbaik di Indonesia

\begin{tabular}{|r|l|l|l|l|}
\hline No & Variabel & Followers & Likes & Ratio \\
\hline 1 & Sandy.ss & 15.200 .000 .000 & 463.300 .000 .000 & 0,033 \\
\hline 2 & Cahyanirynn & 16.200 .000 .000 & 863.500 .000 .000 & 0,019 \\
\hline 3 & Riaricis & 21.100 .000 .000 & 543.800 .000 .000 & 0,039 \\
\hline 4 & Jharnabhagwani & 10.200 .000 .000 & 145.500 .000 .000 & 0,070 \\
\hline 5 & Saalhaerid & 12.200 .000 .000 & 249.200 .000 .000 & 0,049 \\
\hline 6 & Notnot8 & 15.100 .000 .000 & 161.100 .000 .000 & 0,094 \\
\hline 7 & Dinda_ans & 11.500 .000 .000 & 216.900 .000 .000 & 0,053 \\
\hline 8 & Dafaatmja & 10.000 .000 .000 & 138.000 .000 .000 & 0,072 \\
\hline 9 & Juyyputrii21 & 16.400 .000 .000 & 391.400 .000 .000 & 0,042 \\
\hline 10 & Realsesesvana & 8.900 .000 .000 & 135.400 .000 .000 & 0,066 \\
\hline
\end{tabular}

Sumber Pengolah Data Excel

Followers to Likes Ratio memiliki karakteristik yang tinggi, artinya semakin tinggi nilai yang dihasilkan maka semakin baik kredibilitas dari performa akun tersebut. Untuk memberikan peringkat 
pada masing-masing Influencer, peneliti memberikan angka 10 kepada vendor yang mendapatkan nilai tertinggi dan angka 1 untuk vendor yang mendapatkan nilai terendah. Berikut merupakan tabel urutan nilai yang dihasilkan oleh masing - masing Influencer.

Tabel 2. Nilai Variabel Pada Akun Tiktok 10 Influencer Terbaik di Indonesia

\begin{tabular}{|r|l|r|r|}
\hline No & Variabel & Ratio & Tabel Nilai \\
\hline 1 & Sandy.ss & 0,033 & 2 \\
\hline 2 & Cahyanirynn & 0,019 & 1 \\
\hline 3 & Riaricis & 0,039 & 3 \\
\hline 4 & Jharnabhagwani & 0,070 & 8 \\
\hline 5 & Saalhaerid & 0,049 & 5 \\
\hline 6 & Notnot8 & 0,094 & 10 \\
\hline 7 & Dinda_ans & 0,053 & 6 \\
\hline 8 & Dafaatmja & 0,072 & 9 \\
\hline 9 & Juyyputrii21 & 0,042 & 4 \\
\hline 10 & Realsesesvana & 0,066 & 7 \\
\hline
\end{tabular}

Sumber Pengolah Data Excel

Setelah menentukan nilai, selanjutnya menentukan peringkat

\begin{tabular}{|r|l|r|r|}
\hline No & Variabel & Tabel Nilai & Peringkat \\
\hline 1 & Sandy.ss & 2 & 9 \\
\hline 2 & Cahyanirynn & 1 & 10 \\
\hline 3 & Riaricis & 8 & 8 \\
\hline 4 & Jharnabhagwani & 5 & 3 \\
\hline 5 & Saalhaerid & 10 & 6 \\
\hline 6 & Notnot8 & 6 & 1 \\
\hline 7 & Dinda_ans & 9 & 5 \\
\hline 8 & Dafaatmja & & 2 \\
\hline
\end{tabular}




\begin{tabular}{|r|l|r|r|}
\hline 9 & Juyyputrii21 & 4 & 7 \\
\hline 10 & Realsesesvana & 7 & 4 \\
\hline
\end{tabular}

Sumber : Pengolah Data Excel

Dari Tabel Nilai Rasio Akun Tiktok 10 Influencer Terbaik di Indonesia dapat simpulkan bahwa Notnot8 mendapatkan nilai tertinggi untuk rasio Followers to Likes. Sedangkan akun Tiktok Cahyanirynn mendapatkan nilai terendah untuk rasio ini. Jadi, pada penelitian ini Notnot8 memiliki kredibilitas performa yang lebih baik dibandingkan dengan Influencer lainnya.

\section{Kesimpulan}

Tujuan dari penelitian ini adalah mengetahui kredibilitas performa dari akun Tiktok 10 Influencer Terbaik di Indonesia menggunakan Followers to Likes Ratio. 10 Influencer Terbaik di Indonesia tersebut diantaranya : Notnot8, Dafaatmaja, Jharnabhagwani, Realsesesvana, Dinda_ans, Saalhaerid, Juyyputrii21, Riaricis, Sandy.ss, \& Cahyanirynn. Dari kesepuluh Influencer tersebut dapat disimpulkan bahwa :

1. Peringkat pertama diraih oleh Influencer Notnot8 dengan nilai tertinggi yaitu 0,094

2. Peringkat kedua diraih oleh Influencer Dafaatmaja dengan nilai yaitu 0,072

3. Peringkat ketiga diraih oleh Influencer Jharnabhagwani dengan nilai yaitu 0,070

4. Peringkat keempat diraih oleh Influencer Realsesesvana dengan nilai yaitu 0,066

5. Peringkat kelima diraih oleh Influencer Dinda_ans dengan nilai yaitu 0,053

6. Peringkat keenam diraih oleh Influencer Saalhaerid dengan nilai 0,049

7. Peringkat ketujuh diraih oleh Influencer Juyyputrii21 dengan nilai 0,042

8. Peringkat kedelapan diraih oleh Influencer Riaricis dengan nilai 0,039

9. Peringkat kesembilan diraih oleh Influencer Sandy.ss dengan nilai 0,033

10. Peringkat kesepuluh diraih oleh Influencer Cahyanirynn dengan nilai 0,019 DAFTAR PUSTAKA

Fallis, A. . (2013). Pengertian Instagram. Journal of Chemical Information and Modeling, 53(9), 1689-1699.

Ii, B. A. B. (2018). Hubungan Intensitas Penggunaan Media Sosial Dengan Gejala Depresi Mahasiswa Kedokteran (Studi Pada Mahasiswa Kedokteran Tingkat Akhir Yang Menggunakan Kurikulum Modul Terintegrasi). Diponegoro Medical Journal (Jurnal Kedokteran Diponegoro), 7(2), 919934.

Moos. (1984). No Title Детская неврология. Ekp, 13(3), 576.

Structures, M. B. (n.d.). No 主観的健康感を中心とした在宅高齢者における 健康関連指標に関す る共分散構造分析 Title. 1-9.

Wylęgała, L. (2010). No 主観的健康感を中心とした在宅高需者における 健康関連指標に関す る共分散構造分析 Title. 2005, 1-12. 
